\title{
Phytochemical Analysis, Antioxidant, and Anti-Microbial Activities of Suaeda vermiculata $n$-Hexane Extract in Comparison to the Plant's Hydrodistilled Volatile Oil
}

\author{
Mohsen S. Al-Omar ${ }^{1,2, *}$
}

\section{Mohsen S. Al-Omar ${ }^{1,2, *}$}

'Department of Medicinal Chemistry and Pharmacognosy, College of Pharmacy, Qassim University, Buraydah, 51452, KINGDOM OF SAUDI ARABIA.

${ }^{2}$ Medicinal Chemistry and Pharmacognosy Department, Faculty of Pharmacy, JUST, Irbid 22110, JORDAN.

\section{Correspondence}

\section{Mohsen S. AI-Omar}

Department of Medicinal Chemistry and Pharmacognosy, College of Pharmacy, Oassim University, Buraydah, 51452

KINGDOM OF SAUDI ARABIA; Medicinal Chemistry and Pharmacognosy

Department, Faculty of Pharmacy, JUST,

Irbid 22110, JORDAN

\section{E-mail:m.omar@qu.edu.sa}

History

- Submission Date: 02-03-2021:

- Review completed: 15-04-2021;

- Accepted Date: 27-04-2021.

DOI : 10.5530/pj.2021.13.109

\section{Article Available online}

http://www.phcogj.com/v13/i4

\section{Copyright}

() 2021 Phcogj.Com. This is an openaccess article distributed under the terms of the Creative Commons Attribution 4.0 International license.

\begin{abstract}
Background: Suaeda vermiculata, a halophyte found in central Saudi Arabia, used as a remedy for jaundice, liver diseases, and viral infection. Study aim: Chemical identification and biological evaluation for the n-hexane extract of $S$. vermiculata. Methods: An assay of the antimicrobial and antioxidant potentials and contents of the volatile oil and n-hexane extract of the plant's aerial parts were analyzed through GC-MS analysis. Results: A total of 24 constituents representing $73.74 \%$ of the $n$-hexane extract were identified wherein bornyl acetate, $\gamma$-elemene, and phytol were major ratio. The $n$-hexane extract inhibited DPPH-radicals inhibitions at $27 \%$ efficiency at $10 \mathrm{mg} / \mathrm{ml}$ concentration which was lower than the volatile oil DPPH-reactivity. The antimicrobial activity of $n$-hexane extract was relatively weaker than the volatile oil, except against Candida albicans that showed IZD values of $19 \mathrm{~mm}$ with MIC value at $5.2 \mathrm{mg} / \mathrm{ml}$ for the volatile oil while IZD value of $26 \mathrm{~mm}$ and MIC at $4.7 \mathrm{mg} / \mathrm{ml}$ was observed for the $n$-hexane extract. Conclusion: Despite high extractive value, the $n$-hexane as a solvent is not recommended for extraction as the oxygenated-terpenic components, considered responsible for antioxidant and antimicrobial activities were not fully extracted. The $n$-hexane extract which showed potent inhibition of $C$. albicans can be a source for further investigation for bioactivities of its constituents.
\end{abstract}

Key words: Suaeda vermiculata, $n$-hexane extract, Volatile oil, Antimicrobial activity, Antioxidant activity.

\section{INTRODUCTION}

Volatile oils are considered as the main odoriferous components in the plants and are mainly composed of mixtures of different compounds of monoterpenic and/or sesquiterpene hydrocarbons as well as oxygenated hydrocarbons ${ }^{1}$. Due to their important applications in medicinal and cosmetic preparations ${ }^{2}$, volatile oils have been studied from varieties of several thousands of plant species. The extraction, componential analysis, structure, and identification of volatile oil components from their natural sources have been frequently studied (Abad, et al. 2012; Giacometti, et al. 2018). Traditionally, volatile oils are also medicinally used as a remedy for the treatment of several conditions, such as bacterial infections, drowsiness, flatulence, gastritis, body-ache, productive cough, nasal congestion, and urinary tract infections ${ }^{5-8}$. These oils are important components of cosmetics, and pharmaceutical preparations of toothpaste and mouthwashes ${ }^{9,10}$, and are also used as part of salads, food preservatives, and flavoring agents ${ }^{11}$.

Volatile oils have been extracted from several plants by employing different methods which include direct solvent extraction, normal distillation, distillation under vacuum, scarification, and microwave-assisted extractions ${ }^{12-14}$. Also, there have been several other studies conducted to compare the yields and componential efficiencies of the volatile oil extractions by different methods of procurement ${ }^{15-17}$. Some of these studies are focused on the volatile oil production by solvent-based isolation procedures which details the effects of volatile oil constituents of a particular plant ${ }^{14,18}$, as well as changes in the biological activities following the particular isolation procedures ${ }^{19-26}$. According to several other reports, significant changes in the productivity, compositions, and biological activities are well-documented for the volatile oils isolated from particular plants by different isolation procedures. S. vermiculata Forssk. ex. J.F.Gmel. is a halophytic plant growing in the central areas of Saudi Arabia (Mohammed, et al. 2019) is traditionally used as a remedy for liver diseases, jaundice, and infections (Mohammed, et al. 2019; Mohammed 2020a; Mohammed 2020b). Broad-spectrum biological activities have been discovered for $S$. vermiculata, which includes antibacterial, antifungal, and antioxidant $\mathrm{t}^{24,26}$. Also, S. vermiculata contains high proportions of pheophytin, a pigment, which had been known for their significant antioxidant and mild cytotoxic activities ${ }^{22}$. The plant also has economic value as it is used as a camel-feed by nomadic Bedouin ${ }^{22}$.

S. vermiculata volatile oil was investigated in a previous study, and the chemical and biological activity comparisons between two halophytic plants; S. vermiculata and S. cyclophylla were reported $^{23}$. However, due to low oil yield extraction

Cite this article: Al-Omar MS. Phytochemical Analysis, Antioxidant, and Anti-Microbial Activities of Suaeda vermiculata n-Hexane Extract in Comparison to the Plant's Hydrodistilled Volatile Oil. Pharmacog J. 2021;13(4): 853-859. 
by hydrodistillation process from the aerial parts of the S. vermiculata plant, another method employing solvent extraction was planned to maximize the yield and avoid the oil loss during the hydrodistillation process. The current study was planned to investigate the differences in oil quality, contents, and bioactivity of the oils obtained between hydrodistillation and solvent extraction processes of oil procurements from $S$. vermiculata. It employed $n$-hexane as a non-polar solvent for direct extraction in a continued and comparative investigation of the previous report.

\section{MATERIALS AND METHODS}

\section{Plant materials and extraction procedure}

The plant material was collected in September 2017 from Buraydah, Qassim region of Saudi Arabia (Figure 1). The plant was identified by Prof. Dr. Ahmed El-Oglah as S. vermiculata Forssk and the plant sample as number 78 was deposited in the herbarium of the College of Pharmacy, Qassim University. The plant materials were dried in shade for three weeks and grinded to a coarse powder using a mechanical grinder. Accurately, $200 \mathrm{gm}$ of the plant powder were macerated overnight with gentle shaking on a mechanical shaker with $500 \mathrm{ml}$ of $n$-hexane. The $n$-hexane extract was double-filtered using Whatman ${ }^{\mathrm{TM}}$ filter paper and evaporated under vacuum using Rotary evaporator at room temperature. The residue was stored in a $-20^{\circ} \mathrm{C}$ freezer.

\section{Gas chromatography-mass spectroscopy (GC-MS) analysis}

$n$-Hexane extract was analyzed by GC-MS instrument (Shimadzu GCMS-QP2010, Koyoto, Japan) equipped with Rtx-5MS fused bonded column ( $30 \mathrm{~m}$ x $0.25 \mathrm{~mm}$ i.d. x $0.25 \mu \mathrm{m}$ film thickness) (Restek, USA). The analysis conditions for column temperature and flow rate in addition to injector temperature and flow rate of the helium carrier gas were identical to the literature ${ }^{23}$. The mass spectra were recorded under these conditions: filament emission current, $60 \mathrm{~mA}$; ionization voltage, $70 \mathrm{eV}$; ion source, $200^{\circ} \mathrm{C}$. Diluted samples $(1 \% \mathrm{v} / \mathrm{v})$ were injected with split mode (split ratio 1: 15). The data available in the library of the National Institute of Standards and Technology (NIST LIB) was matched to the mass fragmentation spectra of the components. Also, the retention time recorded for the volatile oil constituents in addition to experimental retention index carried out for a series of $n$-alkanes of $\mathrm{C}_{10}$ to $\mathrm{C}_{40}$ hydrocarbons under similar conditions for the volatile oil analysis was used in the volatile oil constituents elucidations in comparison with retention time (RT) and retention indexes (RI) recorded in the literature under similar conditions of the experiments.

\section{Antioxidant activity of $n$-hexane extract against 1 , 1-diphenyl-2-picrylhydrazyl (DPPH)}

The potential ability of $n$-hexane extract to quench free radicals was evaluated against DPPH stable free radicals ${ }^{27}$. Serial dilution from $\mathrm{n}$-hexane extract and positive controls quercetin and Trolox $(100 \mu \mathrm{l})$ were mixed with $1900 \mu \mathrm{l}$ of DPPH solution $(300 \mu \mathrm{M})$. The mixtures were then incubated at room temperature for $20 \mathrm{~min}$. The reduction in the DPPH color was measured at $517 \mathrm{~nm}$ by the spectrophotometer. The method was conducted in triplicate and the scavenging activity of extract and standard were calculated to form the following equation:

Scavenging activity $\%=\left(1-\frac{\mathrm{Ab} \text { (test) }}{\mathrm{Ab} \text { (blank) }}\right) \times 100$

The $\mathrm{Ab}$ (test) is referring to absorbance obtained from the mixture of the test samples with the DPPH solution, Ab (blank) is the absorbance obtained from the DPPH solution only at $517 \mathrm{~nm}$.

Determination of antimicrobial activity

\section{Microorganisms}

Gram-positive bacteria; Staphylococcus aureus, Gram-negative bacteria Escherichia coli, and fungal microorganism; Candida albicans were used in the antimicrobial assay.

\section{Agar well-diffusion method}

Agar well diffusion method was used according to the literature ${ }^{28}$. The prepared microbial suspensions were incubated till showed turbidity comparable to the reference, $0.5 \mathrm{McF}$ arland tube. The agar surface was smeared with sterile swaps and incubated for a few minutes. Accurately,

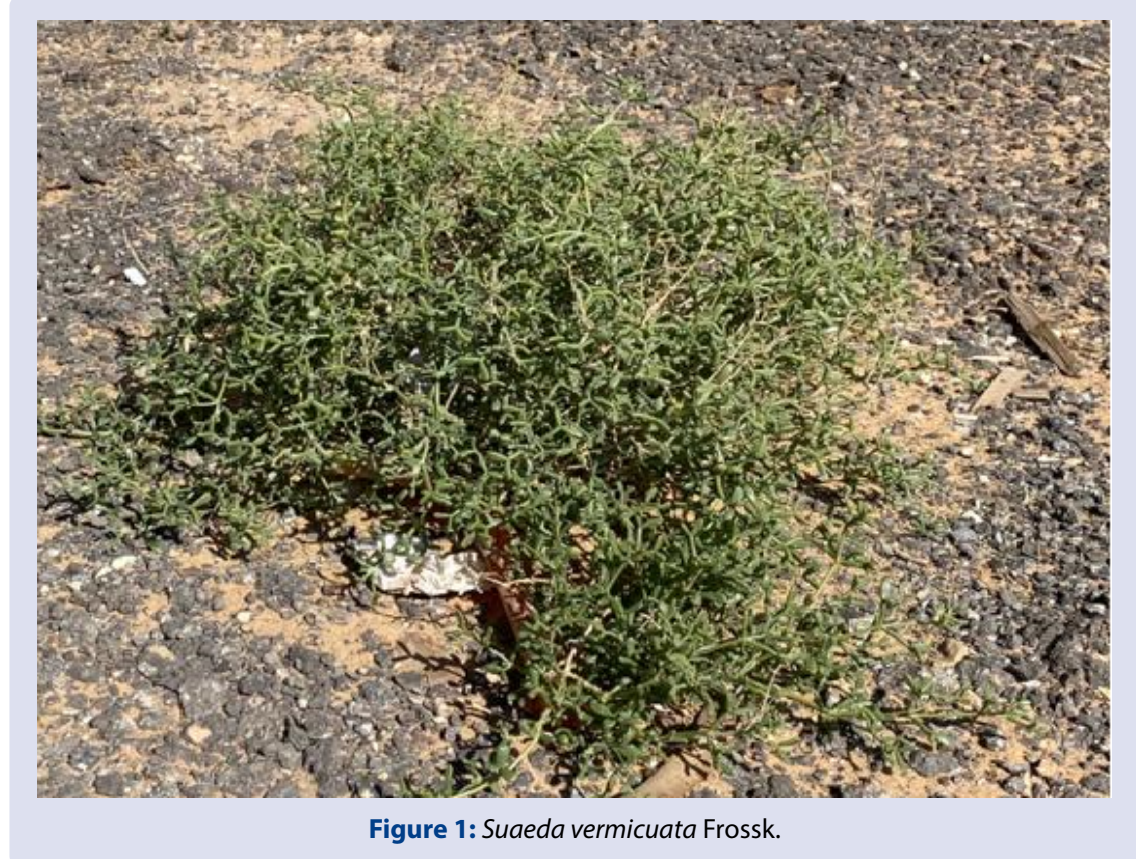


$50 \mu \mathrm{l}$ of the $\mathrm{n}$-hexane extract $(10 \mathrm{mg} / \mathrm{ml}$ in DMSO) was micropipette to the designed cups. Positive control drug discs $(10 \mu \mathrm{g} / \mathrm{ml}$ amoxicillin, gentamycin and clotrimazole) were used as positive controls. Plates were then incubated (Sheldon Manufacturing INC., USA) for 24-72 hours and were checked every $24 \mathrm{~h}$ for the growth of microorganisms. Inhibition zone diameters (IZD) were visualized and measured to the nearest millimeter.

\section{Minimal inhibitory concentration (MIC) measurement}

MIC was measured similarly to the method described in the antimicrobial assay of $S$. vermiculata volatile oil ${ }^{23}$. The bacterial microorganisms were incubated at $37^{\circ} \mathrm{C}$ for $24 \mathrm{~h}$ in Mueller Hinton broth supplemented with Tween 80 detergent (final concentration of $0.5 \%$ (v/v), while Candida albicans was incubated at $30^{\circ} \mathrm{C}$ for $24 \mathrm{~h}$ in Sabouraud dextrose broth-SDB + Tween 80 . Serial dilutions of volatile oils were prepared in a 96-well microplate. Also, one growth control (MHB + Tween 80$)$ and one sterility control (MHB + Tween $80+$ test oil) were prepared. Plates were incubated at $37^{\circ} \mathrm{C}$ for $24 \mathrm{~h}$ for bacteria and at $30^{\circ} \mathrm{C}$ for $48 \mathrm{~h}$ for the Candida albicans. The white turbidity in the well bottom indicates bacterial growth ${ }^{29}$.

\section{RESULTS AND DISCUSSION}

Due to volatile oil's importance and applications in the medical, culinary, and industrial fields, researchers have been interested in volatile oil studies (Böhme, et al. 2014; Hanif, et al. 2019). Comparison between extraction procedures aimed to enhance the yields and quality of the volatile oils were one of the major investigational interests ${ }^{30-33}$. $S$. vermiculata is an important halophytic plant used in traditional medicine in inflammation, pain, and liver disorders as well as is used as camels' feed ${ }^{22}$. The antimicrobial and antioxidant activities of $S$. vermiculata volatile oils isolated by hydrodistillation technique was investigated earlier (Mohammed, et al. 2019). Also, the antimicrobial activity of $S$. vermiculata volatile oil against $P$. aeruginosa and E. coli Gram-negative bacteria in addition to Candida albicans was confirmed (Mohammed, et al. 2019). The study also confirmed that $S$. vermiculata volatile oil prepared by hydrodistillation was inactive against Grampositive bacteria S. pyogenes, S. epidermidis, and S. aureus ${ }^{23}$.

The volatile oil constituents of $S$. vermiculata were extracted by $n$-hexane non-polar solvent, analyzed by GC-MS, and compared to the plant volatile constituents, obtained as oil, isolated by hydrodistillation procedure. The odor of $n$-hexane extract of $S$. vermiculata after complete dryness was similar to the odor of the volatile oils obtained from the plant by hydrodistillation. However, the color of the n-hexane extract was yellowish-green in contrast to the volatile oil yellowishbrown color. The greenish color of the $n$-hexane extract might have been retained due to the presence of a high proportion of the darkgreen pheophytin, a pigment found in the plant (Mohammed, et al. 2019). The higher lipophilic character of the pheophytin has potential for its partial solubility in the $n$-hexane extract ${ }^{22}$ and thus retained in the extract. The yields obtained from the $n$-hexane extraction of $S$. vermiculata was comparatively higher than that obtained from the hydrodistillation procedure. The yield percentage from the hydrodistillation was reported as $0.11 \%$ (225 mg oil out of $200 \mathrm{gm}$ of the plant dried powder) ${ }^{23}$ in comparison to $0.87 \%$ (1756 mg extract out of $200 \mathrm{gm}$ of the dried plant powder) obtained from the $n$-hexane extraction of the plant. The higher yield obtained from $n$-hexane extract is mainly attributed to the presence of the volatile and the non-volatile substances that have been extracted by the $n$-hexane.

The results of GC-MS analyses of $n$-hexane extract of $S$. vermiculata hydrodistillation (Table 1) revealed that $n$-hexane as a solvent has a better capability to extract more compounds that can affect the biological activity. The total identified compounds in $n$-hexane extract of S. vermiculata by GC-MS analysis were twenty-four which represented
$73.74 \%$ of the extract weight. In contrast to the reported compounds in the oil obtained by the hydrodistillation process, more products were identified in the n-hexane extract. The presence of hexenal, camphene, hexanoic acid, methyl decanoate, elemol, nonadecane, phytol, tricosane, pentacosane, hexacosane, heptacosane, $\beta$-sitosterol, and $\beta$-amyrin were exclusive to the $n$-hexane extract composition. However, some of these compounds were identified with a high proportional percentage such as nonadecane and phytol which were represented by $4.51 \%$ and $10.14 \%$, respectively. The presence of phytol, $\beta$-amyrin, and $\beta$-sitosterol in the $n$-hexane extract of $S$. vermiculata is also compatible with the reported phytochemicals isolated from the plant (Mohammed, et al. 2019). The results in table 1 for the relative percentage of some monoterpenes also reflected the differences between the non-polar extraction and hydrodistillation process of $S$. vermiculata to yield the volatile oil.

For instance, linalool, fenchol, $\beta$-terpineol, borneol, and terpinen4-ol were only represented in the hydro-distillate of the plant. Also, some of the volatile constituents were more represented in the plant hydrodistillation product such as eucalyptol, camphor, and $\alpha$-terpineol that showed $4.49,28.74$, and $22.78 \%$ in the plant distillate in contrast to $0.85,2.76$, and $5.47 \%$ in $n$-hexane extract of $S$. vermiculata respectively. These results reflected the inability of $n$-hexane and a non-polar solvent to extract alcoholic monoterpenes which could be more extracted by the more polar organic solvents such as ethyl acetate and methanol ${ }^{30,31}$. This proposition was also supported by the relative percentage of $a$-terpinene and bornyl acetate which were more represented in $n$-hexane extract (Table 1). Also, the relative percentage of total oxygenated monoterpenes and sesquiterpenes showed in Table 1 indicated that the hydrodistillation process is preferred to recover monoterpenes while non-polar solvents such as $n$-hexane are recommended for the sesquiterpenes extractions. The overall results in Table 1 reflected the ability of $n$-hexane to dissolve some of the plant's volatile oil constituents and the potential capability of the solvent to recover the higher non-volatile constituents of the plant such as phytol and $\beta$-sitosterol.

\section{Anti-oxidant activity of $S$. vermiculata $n$-hexane extract and volatile oils distillate}

The $n$-hexane extract of $S$. vermiculata was compared to the published data of the plant volatile oil (Mohammed, et al. 2019). The results in Figure 2 revealed that $S$. vermiculata volatile oil was more active in quenching DPPH free radicals at higher concentrations than the $n$-hexane extraction product. The differences in the antioxidant activity of $n$-hexane extract and volatile oil distillate of $S$. vermiculata are mostly related to the presence of high proportions of oxygenated monoterpenes in the volatile oil distillate of the plant compared to the non-polar extract obtained by $n$-hexane $e^{30,31}$. The presence of high proportions of a-terpineol, camphor, and borneol in the volatile oil distillate is also one of the reasons for the activity of $S$. vermiculata volatile oil distillate over $n$-hexane extract ${ }^{34}$. Figure 2 also showed weak DPPH-radicals quenching activity for the $n$-hexane extract of $S$. vermiculata compared to BHA, only at the higher concentrations 2.5 to $10 \mathrm{mg} / \mathrm{ml}$ ) while volatile oil distillate of the plant comparatively quenched DPPH-free radicals better than BHA but significantly lower than quercetin.

\section{Antimicrobial activity of $S$. vermiculata $n$-hexane extract and volatile oils distillate}

The antimicrobial activity of $n$-hexane extract of $S$. vermiculata was tested by two different methods against microbial pathogens of Grampositive, Gram-negative, and C. albicans fungal microorganisms. The results were compared to the reported data of the volatile oil distillate of the plant. Results in Table 2 revealed higher antimicrobial activities for the volatile oil distillate over the $n$-hexane extract of the plant, e.g., $n$-hexane extract was inactive against $S$. pyogenes, S. epidermidis which 
Table 1: Chemical composition of the $n$-hexane extract of $S$. vermiculata Forssk herb.

\begin{tabular}{|c|c|c|c|c|}
\hline Name & $\mathrm{RI}^{\mathrm{E}}$ & $\left.R\right|^{R}$ & $\%$ RP (n-hexane extract) & \%RP (hydrodistillation)* \\
\hline Hexenal & 805 & 806 & 0.09 & \\
\hline Camphene & 943 & 943 & 0.33 & \\
\hline a-Terpinene & 1016 & 1016 & 2.44 & 0.35 \\
\hline Hexanoic acid & & & 0.23 & \\
\hline Eucalyptol & 1029 & 1031 & 0.85 & 4.49 \\
\hline Linalool & 1100 & 1082 & & 0.89 \\
\hline Fenchol & 1114 & 1120 & & 0.44 \\
\hline trans-Pinocarveol & 1140 & 1140 & 0.11 & 0.74 \\
\hline Camphor & 1145 & 1149 & 2.76 & 28.74 \\
\hline$\beta$-Terpineol & 1149 & 1158 & & 0.5 \\
\hline $\begin{array}{l}\text { Isocamphopinone } \\
\text { (mono ketone) }\end{array}$ & 1161 & 1170 & 0.82 & 0.24 \\
\hline Borneol & 1167 & 1170 & & 33.77 \\
\hline Terpinen-4-ol & 1178 & 1178 & & 2.38 \\
\hline Neoisomenthol & 1186 & 1188 & & 0.34 \\
\hline$a$-Terpineol & 1191 & 1197 & 5.47 & 22.78 \\
\hline Dodecane & 1196 & 1199 & 3.68 & 1.18 \\
\hline Bornyl acetate & 1288 & 1286 & 11.04 & 0.68 \\
\hline Methyl decanoate & & 1325 & 3.15 & \\
\hline$\beta$-Damascenone & 1387 & 1383 & 2.66 & 0.49 \\
\hline$\gamma$-Elemene & 1431 & 1432 & 9.55 & 1.17 \\
\hline Elemol & & 1545 & 7.12 & \\
\hline trans-Longipinocarveol & 1667 & 1651 & 1.72 & 0.82 \\
\hline Nonadecane & 1902 & 1900 & 4.51 & \\
\hline Phytol & 2130 & 2129 & 10.14 & \\
\hline Tricosane & 2312 & 2300 & 2.11 & \\
\hline Pentacosane & 2509 & 2500 & 0.94 & \\
\hline Hexacosane & 2605 & 2600 & 0.71 & \\
\hline Heptacosane & 2702 & 2700 & 0.16 & \\
\hline$\beta$-Sitosterol & 3327 & 3327 & 2.21 & \\
\hline \multirow[t]{5}{*}{ a-Amyrin } & 3390 & 3386 & 0.94 & \\
\hline & Total \% & & 73.74 & 100 \\
\hline & Oxygenated Monoterpenes & & 21.37 & 95.99 \\
\hline & Monoterpene Ketones & & 3.76 & 28.98 \\
\hline & Monoterpene Alcohols & & 17.70 & 61.84 \\
\hline
\end{tabular}

"Reported results obtained from Mohammed et al. $2019^{23}$

${ }^{E}$ Experimental Retention index $(R I)$ using a series of $\mathrm{n}$-alkanes $\left(\mathrm{C}_{10}-\mathrm{C}_{40}\right)$ under identical experimental conditions.

${ }^{R}$ Reported retention index according to the NIST library and published literature data calculated under identical experimental condition

\section{Table 2: Antimicrobial Activity of the n-hexane extract of S. vermiculata Forssk Herb.}

\begin{tabular}{|c|c|c|c|c|c|c|c|}
\hline \multirow{2}{*}{$\begin{array}{c}\text { Extract } \\
\text { Microorganism }\end{array}$} & \multicolumn{2}{|c|}{ Volatile oil distillate * } & \multicolumn{2}{|c|}{ n-hexane extract } & \multirow[t]{2}{*}{ Gentamycin } & \multirow{2}{*}{$\begin{array}{c}\text { Amoxicillin } \\
\text { IZD }\end{array}$} & \multirow[t]{2}{*}{ Clotrimazole } \\
\hline & IZD $^{* *}$ & $\mathrm{MIC}^{\mathrm{b}}$ & IZD & MIC & & & \\
\hline Streptococcus pyogenes & 7 & na & na & nd & nd & nd & nd \\
\hline Staphylococcus epidermidis & 9 & na & na & nd & 16 & nd & nd \\
\hline Staphylococcus aureus & nd & na & na & nd & 20 & 9 & nd \\
\hline Pseudomonas aeruginosa & 15 & $66 \pm 3.1$ & $10 \mathrm{~mm}$ & $105 \pm 4.15$ & 9 & 15 & nd \\
\hline Escherichia coli & 10 & $85 \pm 2.2$ & $7 \mathrm{~mm}$ & $197.5 \pm 12.8$ & 14 & 13 & nd \\
\hline Candida albicans & 19 & $5.2 \pm 2.7$ & $26 \mathrm{~mm}$ & $4.7 \pm 2.1$ & nd & nd & 16 \\
\hline
\end{tabular}

${ }^{*}$ Reported results obtained from Mohammed et al, $2019{ }^{23}{ }^{*}$ IZD were conducted in triplicate and calculated to the nearest mm inhibition including the well or disk $(6 \mathrm{~mm})$. na= not active at the higher dose, $\mathrm{nd}=$ not determined. 
Al-Omar, et al: Phytochemical Analysis, Antioxidant, and Anti-Microbial Activities of Suaeda vermiculata n-Hexane Extract in Comparison to the Plant's Hydrodistilled Volatile Oil

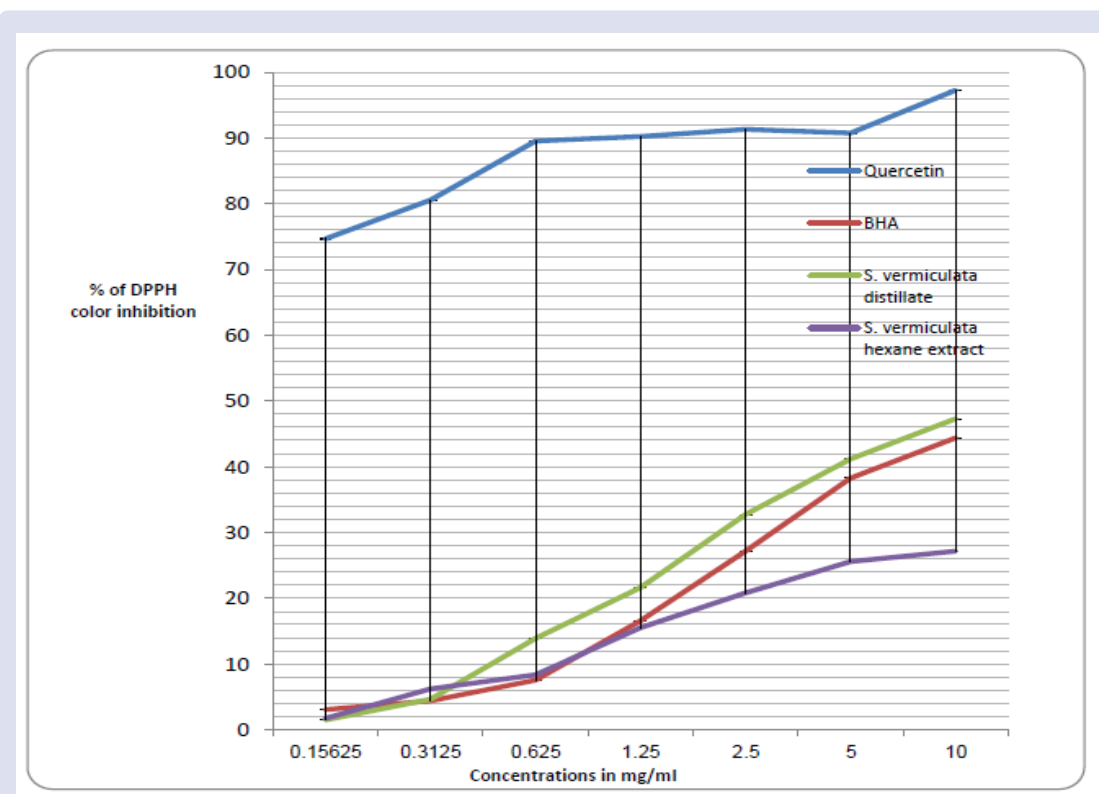

Figure 2: Scavenging Effect of the S. vermiculata $n$-hexane extract and volatile oils distillate.

were weakly inhibited by the volatile oil distillate with IZD values of 7 and $9 \mathrm{~mm}$, respectively. Similar results were also shown for the effects of the plant on P. aeruginosa and E. coli where volatile oil distillate was moderately inhibiting their growth with IZD values of 15 and $10 \mathrm{~mm}$ and MIC values at 66 and $85 \mathrm{mg} / \mathrm{ml}$, respectively. However, $n$-hexane extract weakly inhibited the growth of these bacterial microorganisms with IZD values of 19 and $26 \mathrm{~mm}$ and MIC values 105 and $197 \mathrm{mg} / \mathrm{ml}$, respectively. Furthermore, Both plant products, i.e., volatile oil distillate and $n$-hexane extract actively inhibited the growth of fungal strain, $C$. albicans with IZD values of 19 and $26 \mathrm{~mm}$ and MIC values 5.2 and 4.7 $\mathrm{mg} / \mathrm{ml}$, respectively.

\section{CONCLUSION}

The current study provides in-depth chemical and biological activity comparisons between the $n$-hexane extract and volatile oil distillate of $S$. vermiculata. More constituents were identified in the $n$-hexane extract of $S$. vermiculata than the plant's volatile oil distillate. Oxygenated monoterpenes were abundant in the volatile oil distillate while sesquiterpenes and aliphatics were more encountered in the $n$-hexane extract. Overall results concluded that $n$-hexane extract of the plant was less active than the volatile oil distillate as an antioxidant and antimicrobial agents. The better activities of the volatile oil distillate are considered mostly related to the higher abundance of oxygenated monoterpenes in the oil.

\section{ACKNOWLEDGEMENT}

The author is gratefully thankful to Prof. Dr. Ahmed El-Oglah for the identification of the plant material.

\section{REFERENCES}

1. Başer KHC, Demirci F. Chemistry of essential oils. Flavours Fragrances Chem Bioprocess Sustain Ed by Berger RG New York Springer. 2007:43-86.

2. Mohammed HA, Al-Omar MS, Mohammed SAA, Aly MSA, Alsuqub ANA, Khan RA. Drying Induced Impact on Composition and Oil Quality of Rosemary Herb, Rosmarinus Officinalis Linn. Molecules. 2020;25(12):2830.

3. Giacometti J, Kovačević DB, Putnik P. Extraction of bioactive compounds and essential oils from mediterranean herbs by conventional and green innovative techniques: A review. Food Res Int. 2018;113:245-62.
4. Abad MJ, Bedoya LM, Apaza L, Bermejo P. The Artemisia L. genus: a review of bioactive essential oils. Molecules. 2012;17(3):2542-66.

5. Bag A, Bhattacharyya S, Chattopadhyay R. Medicinal plants and urinary tract infections: An update. Pharmacogn Rev. 2008;2(4):277.

6. Ali B, Al-Wabel NA, Shams S, Ahamad A, Khan SA, Anwar F. Essential oils used in aromatherapy: A systemic review. Asian Pac J Trop Biomed. 2015;5(8):601-11.

7. Ahmed K, Shaheen G, Asif HM. Zingiber officinale Roscoe (pharmacological activity). J Med Plants Res. 2011;5(3):344-8.

8. Dorman HJD, Deans SG. Antimicrobial agents from plants: antibacterial activity of plant volatile oils. J Appl Microbiol. 2000;88(2):308-16.

9. Vranić E, Lačević A, Mehmedagić A, Uzunović A. Formulation ingredients for toothpastes and mouthwashes. Bosn J basic Med Sci. 2004;4(4):51-8.

10. Mohammed HA, Abdel-Aziz MM, Hegazy MM. Anti-oral pathogens of tecoma stans (L.) and cassia javanica (I.) flower volatile oils in comparison with chlorhexidine in accordance with their folk medicinal uses. Med. 2019;55(6).

11. Preedy VR. Essential Oils in Food Preservation, Flavor and Safety. Academic Press; 2015.

12. Kaufmann B, Christen P. Recent extraction techniques for natural products: microwave-assisted extraction and pressurised solvent extraction. Phytochem Anal An Int J Plant Chem Biochem Tech. 2002;13(2):105-13.

13. Cho S-K, El-Aty AMA, Choi J-H, Kim MR, Shim JH. Optimized conditions for the extraction of secondary volatile metabolites in Angelica roots by accelerated solvent extraction. J Pharm Biomed Anal. 2007:44(5):1154-8.

14. Teng $\mathrm{H}$, Lee WY. Antibacterial and antioxidant activities and chemical compositions of volatile oils extracted from Schisandra chinensis Baill. seeds using simultaneous distillation extraction method, and comparison with Soxhlet and microwave-assisted extraction. Biosci Biotechnol Biochem. 2014;78(1):79-85.

15. Lucchesi ME, Chemat F, Smadja J. Solvent-free microwave extraction of essential oil from aromatic herbs: comparison with conventional hydro-distillation. J Chromatogr a. 2004;1043(2):323-7.

16. Craveiro AA, Matos FJA, Alencar JW, Plumel MM. Microwave oven extraction of an essential oil. Flavour Fragr J. 1989;4(1):43-4.

17. Kahriman N, Tosun G, Genc H, Yayli N. Comparative essential oil analysis of Geranium sylvaticum extracted by hydrodistillation and microwave distillation. Turkish J Chem. 2010;34(6):969-76. 
18. Bousbia N, Vian MA, Ferhat MA, Petitcolas E, Meklati BY, Chemat F. Comparison of two isolation methods for essential oil from rosemary leaves: Hydrodistillation and microwave hydrodiffusion and gravity. Food Chem. 2009;114(1):355-62.

19. Okoh OO, Sadimenko AP, Afolayan AJ. Comparative evaluation of the antibacterial activities of the essential oils of Rosmarinus officinalis L. obtained by hydrodistillation and solvent free microwave extraction methods. Food Chem. 2010;120(1):308-12.

20. Tigrine-Kordjani N, Chemat F, Meklati BY, Tuduri L, Giraudel JL, Montury M. Relative characterization of rosemary samples according to their geographical origins using microwave-accelerated distillation, solid-phase microextraction and Kohonen self-organizing maps. Anal Bioanal Chem. 2007;389(2):631-41.

21. Erkan N, Tao Z, Rupasinghe HPV, Uysal B, Oksal BS. Antibacterial activities of essential oils extracted from leaves of Murraya koenigii by solvent-free microwave extraction and hydro-distillation. Nat Prod Commun. 2012;7(1):1934578X1200700139.

22. Mohammed HA, Al-Omar MS, El-Readi MZ, Alhowail AH, Aldubayan MA, Abdellatif AAH. Formulation of Ethyl Cellulose Microparticles Incorporated Pheophytin A Isolated from Suaeda vermiculata for Antioxidant and Cytotoxic Activities. Molecules. 2019;24(8):1501.

23. Mohammed HA, Al-Omar MS, Aly MSA, Hegazy MM. Essential Oil Constituents and Biological Activities of the Halophytic Plants, Suaeda Vermiculata Forssk and Salsola Cyclophylla Bakera Growing in Saudi Arabia. J Essent Oil Bear Plants. 2019:1-12.

24. Mohammed HA. The Valuable Impacts of Halophytic Genus Suaeda Nutritional, Chemical, and Biological Values. Med Chem. 2020.

25. Mohammed HA. Behavioral Evaluation for Aqueous and Ethano Extracts of Suaeda vermiculata Forssk. Cent Nerv Syst Agents Med Chem. 2020.

26. Al-Saleh GFS, Gamal El-Din AY, Abbas JA, Saeed NA. Phytochemical and Biological Studies of Medicinal Plants in Bahrain: The Family Chenopodiaceae-Part 2. Int J Pharmacogn. 1997;35(1):38-42.
27. Hosny M, Johnson HA, Ueltschy AK, Rosazza JPN. Oxidation, reduction, and methylation of carnosic Acid by nocardia. J Nat Prod. 2002;65(9):1266-9

28. Cooper KE, Woodman D. The diffusion of antiseptics through agar gels, with special reference to the agar cup assay method of estimating the activity of penicillin. J Pathol Bacteriol. 1946;58(1):7584

29. Mohammed HA, Al-Omer MS, Ahmed AM. Comparative Study for the Volatile Oil Constituents and Antimicrobial Activity of Rhanterium epapposum Oliv. Growing in Qassim, Saudi Arabia. Pharmacogn J. 2019;11(1).

30. Böhme K, Barros-Velázquez J, Calo-Mata P, Aubourg SP. Antibacterial, antiviral and antifungal activity of essential oils: Mechanisms and applications. In: Antimicrobial Compounds. Springer; 2014:51-81.

31. Hanif MA, Nisar S, Khan GS, Mushtaq Z, Zubair M. Essential Oils. In: Essential Oil Research. Springer; 2019:3-17.

32. Nekoei M, Mohammadhosseini M. Chemical Composition of the Essential Oils and Volatiles of Salvia leriifolia by Three Different Extraction Methods Prior to Gas Chromatographic-Mass Spectrometric Determination: Comparison of HD with SFME and HS-SPME. J Essent Oil Bear Plants. 2017;20(2):410-425.

33. Mohammadhosseini M, Akbarzadeh A, Hashemi-Moghaddam $H$ Nafchi AM, Mashayekhi HA, Aryanpour A. Chemical composition of the essential oils from the aerial parts of Artemisia sieber by using conventional hydrodistillation and microwave assisted hydrodistillation: A comparative study. J Essent Oil Bear Plants. 2016:19(1):32-45.

34. Ruberto G, Baratta MT. Antioxidant activity of selected essential oil components in two lipid model systems. Food Chem. 2000;69(2):16774. 


\section{GRAPHICAL ABSTRACT}

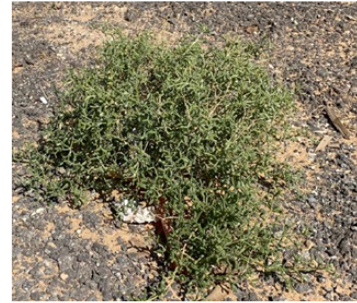

Suaeda vermiculata

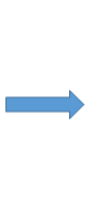

n-hexane extract

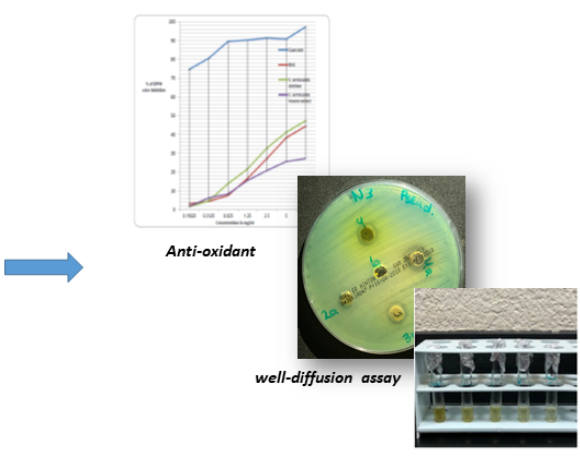

MIC

\section{ABOUT AUTHORS}

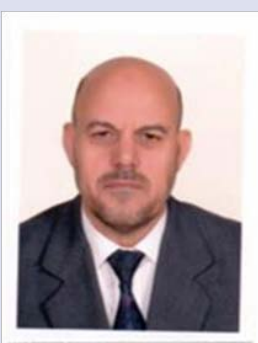

PhD Degree in Pharmacy (Med. and Nat. Prod. Chemistry), Univ. of lowa, USA, 1994. Assistant Dean, 1996-1998; Chairman of Medicinal Chemistry and Pharmacognosy Department, Faculty of Pharmacy, JUST, Jordan, 2003-2006 Associate Professor, Faculty of Pharmacy, Applied Sciences University, Amman, Jordan 2009- 2010; Associate Professor, Faculty of Pharmacy, Umm UI-Qura University, Mecca, KSA 2010- 2012; Associate Professor \& Dept. Supervisor, Faculty of Pharmacy, Qassim University, KSA, 2013-2019.

The research interest focused on chemistry of natural products and their biological evaluation (0000-0001-8134-

9623). Patent registration in the United States patent and trademark office with a serial No. 08/413,797.

Cite this article: Al-Omar MS. Phytochemical Analysis, Antioxidant, and Anti-Microbial Activities of Suaeda vermiculata n-Hexane Extract in Comparison to the Plant's Hydrodistilled Volatile Oil. Pharmacog J. 2021;13(4): 853-859. 